\title{
Leiomyosarcoma Complicating Chronic Inflammation of the Testis
}

\author{
Y. Alia E.O. Kehindea R. Makarb K.A. Al-Awadia J.T. Animb \\ Departments of aSurgery (Urology Division) and bPathology, MubarakAI-Kabir Hospital and Faculty of Medicine, \\ Kuwait University, Kuwait
}

\section{Key Words}

Leiomyosarcoma · Testis · Risk factor · Chronic

inflammation

\begin{abstract}
Objective: To report on a case of leiomyosarcoma of the testis that appeared to have arisen from a background of chronic testicular inflammation. Clinical Presentation: A 65-year-old man with a 15-year history of diabetes mellitus and low-grade discomfort and swelling in the right testis presented as an emergency with exacerbation of the pain and swelling of the testis. Repeated ultrasound examination of the testis in the past 5 years had suggested a chronic testicular inflammatory disorder. Ultrasound during the current emergency case admission revealed a normal left testis, but a large heterogeneous solid mass with a moderate intratesticular calcification in the right testis and the presence of a moderate hydrocele. Serum $\alpha$-fetoprotein and $\beta$-human chorionic gonadotropin were normal. A right radical orchidectomy was performed. Histopathology and immunohistochemistry revealed primary leiomyosarcoma of the right testis. There was no spermatic cord or venous involvement. One year after orchidectomy there was no sign of metastasis. Conclusion: Radical orchidectomy followed by surveillance appears to be the treatment of choice for this
\end{abstract}

testicular leiomyosarcoma, which seemed to have run an indolent course compared to other testicular tumours.

Copyright $@ 2002$ S. Karger AG, Basel

\section{Introduction}

Leiomyosarcoma is known to arise anywhere in the body from tissues containing smooth muscle [1]. As a group, soft tissue sarcomas account for about $1 \%$ of all human cancers [2]. Intratesticular leiomyosarcoma is very rare, as to date only about 5 cases have been reported [1, 3 , 4]. It tends to affect elderly males in the 6th-7th decades. The aetiology of this tumour is not known, but prolonged use of anabolic steroids has been suggested as a possible risk factor $[3,5,6]$.

We report a case of primary leiomyosarcoma of the testis that appeared to have arisen from a backgound of chronic inflammation of the testis of 15 years duration. Generally testicular leiomyosarcoma is a tumour which appears to run a more indolent course compared to other testicular tumours, like teratoma and seminoma.

Dr. E.O. Kehinde, MBBS, FRCS, MD

Department of Surgery, Faculty of Medicine

Kuwait University, PO Box 24923

Safat 13110 (Kuwait)

Tel. +965 5319030, Fax +965 5319597, E-Mail ekehinde@hsc.kuniv.edu.kw 

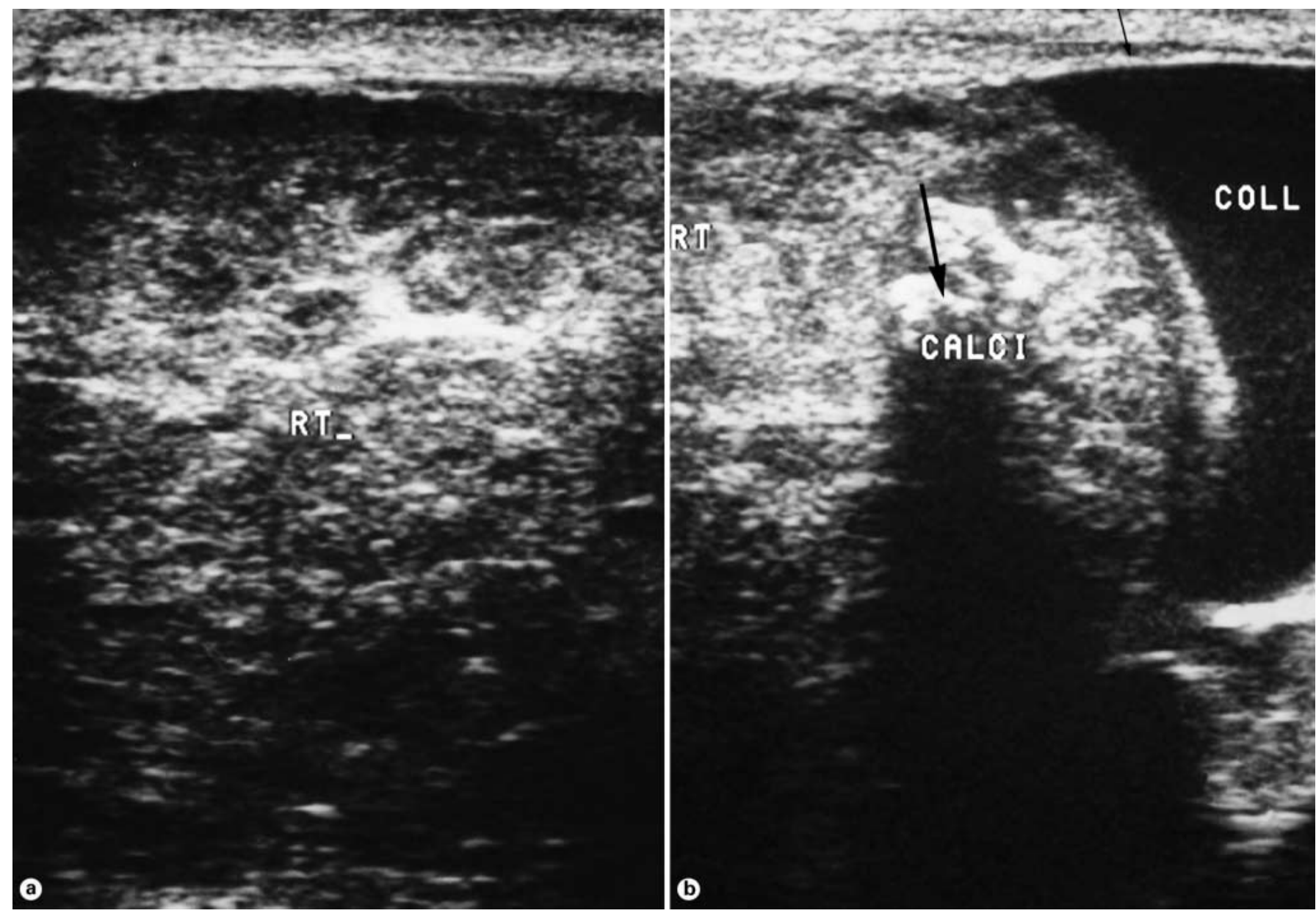

Fig. 1. a Ultrasound of testis showing multiple cysts in the right testis. b Ultrasound of testis showing moderate-sized hydrocele (thin arrow), intratesticular calcification with acoustic shadowing (fat black arrow).

\section{Case Report}

A 65-year-old man was admitted to the emergency department, complaining of painful right scrotal swelling and lower abdominal pain associated with a fever of 5 days' duration. He admitted to having had the scrotal swelling for about 15 years. During the past 5 years, ultrasound examinations revealed inflammation of the testis. The swelling had become more painful in the past 4 weeks. He denied any history of recurrent fever. He is a known diabetic with hypertension of 10 years' duration. Physical examination revealed an obese elderly man, with a temperature of $38.3^{\circ} \mathrm{C}$. There was cellulitus in the suprapubic region. The left test is was normal. However, there was a large, tender, right scrotal mass $(6 \times 7 \mathrm{~cm})$. Blood examination revealed a white blood cell count of $17.3 \times 10^{9} / 1$ (normal $4-11 \times$ $10^{9} / \mathrm{l}$ ) and an erythrocyte sedimentation rate of $112 \mathrm{~mm} / \mathrm{h}$ (normal 1-4 $\mathrm{mm} / \mathrm{h}$ in males), and a normal renal profile. His blood sugar level was over $20 \mathrm{mmol} / \mathrm{l}$ (normal 3.9-6.1 mmol/l), liver function tests revealed low albumin of $24 \mathrm{~g} / \mathrm{l}$ (normal $35-47 \mathrm{~g} / \mathrm{l}$ ) and total bilirubin of $39 \mu \mathrm{mol} / \mathrm{l}$ (normal 3-20 $\mu \mathrm{mol} / \mathrm{l}$ ). Alpha-fetoprotein and $\beta$-human chorionic gonadotropin were normal. C-reactive protein was $10 \mathrm{mg} / \mathrm{l}$ (normal $<8 \mathrm{mg} / \mathrm{l}$ ).

Ultrasound of the scrotum confirmed a normal left testis, and a large, heterogeneous, solid mass replacing the right testis, with moderate hydrocele and intratesticular calcification (fig. 1a, b). He was given intravenous (i.v.) ciprofloxacin $500 \mathrm{mg}$ 12-hourly. An emergency inguinal exploration of the right testis was performed because of septicaemia not responding to i.v. antibiotics. Findings at surgery included microabscesses in the suprapubic fatty tissue and a large irregular right testicular mass, which looked neoplastic. The microabscesses could probably be coincident cellulitis in a diabetic patient. A right radical orchidectomy was carried out. Postoperatively, he developed Fournier's gangrene, which required generous debridement, to which he responded well. A postoperative CT scan of the chest and abdomen showed no lymph node metastasis. The patient remained well 1 year after orchidectomy, with no sign of local recurrence or metastasis. 

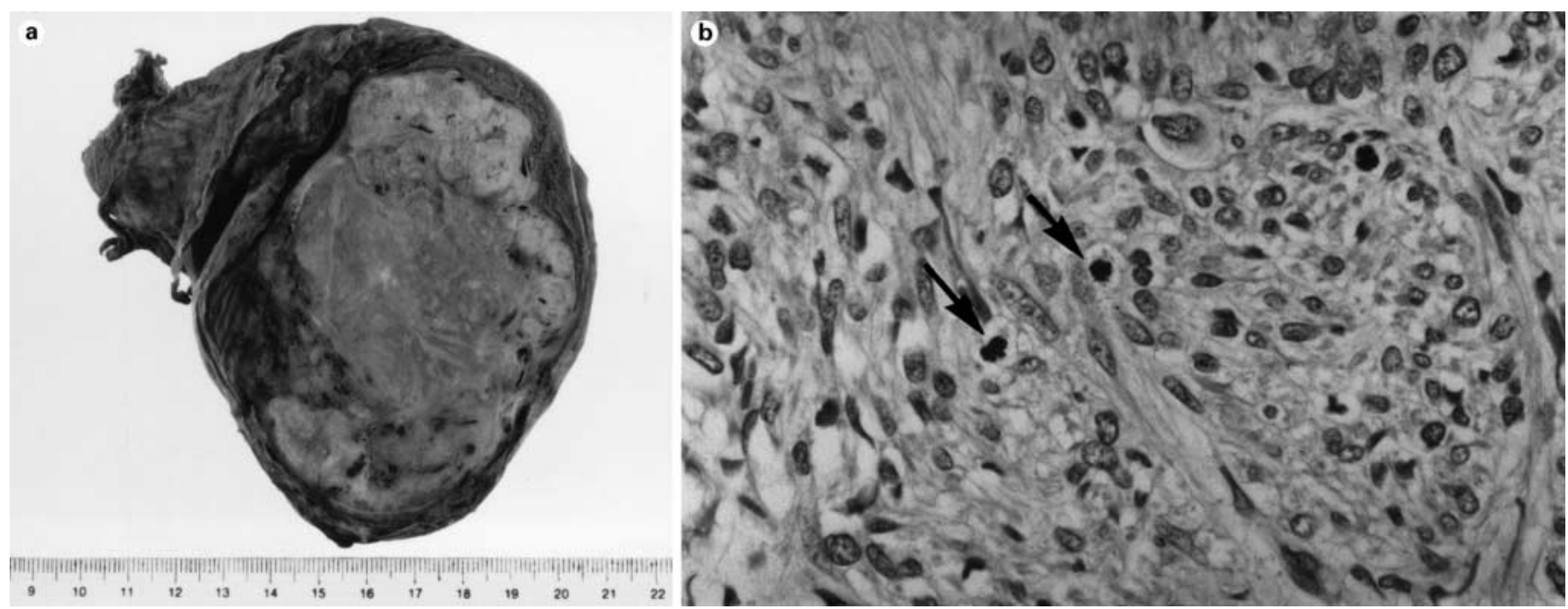

Fig. 2. a Photograph showing a nodular mass replacing testis. b Photomicrograph of testicular tumour showing fascicles of malignant spindle cells. Mitotic figures are shown by arrows $. \mathrm{HE}, \times 400$.

\section{Pathological Findings}

The resected specimen consisted of a mass weighing $320 \mathrm{~g}$ and measuring approximately $12 \times 9 \times 5 \mathrm{~cm}$, with what appeared to be an attached stump of the spermatic cord measuring $6.5 \times 3.0 \mathrm{~cm}$ (fig. 2a). The cut surface showed a variegated appearance with greyish and yellowish areas. There was no grossly identifiable testicular tissue. Histology showed chronic inflammatory cell infiltrate adjacent to a spindle-celled tumour with cells arranged in fascicles. Foci of necrosis and dystrophic calcification were also present. There was moderate pleomorphism of the tumour cells, with increased mitotic activity ( $>2 \mathrm{pHF}$ ) (fig. 2b). A peripheral rim of recognizable testicular tissue showed seminiferous tubules containing early spermatocytes only as well as attenuated epididymis within a thickened fibrous capsule, with an adjacent artery showing medial calcification. The spermatic cord contained no tumour deposits. Immunohistochemistry of the tumour was positive for desmin, smooth muscle actin, and vimentin but negative for myoglobin and S-100 protein. A diagnosis of primary leiomyosarcoma of the testis was made.

\section{Discussion}

In this diabetic patient, the most probable risk factor for leiomyosarcoma was chronic inflammation of about 15 years' duration. As the patient claimed that he had had the right testicular swelling for about 15 years, and that he had had repeated ultrasound examinations of the testis in the previous 5 years, it is unlikely that a testicular tumour had been missed since ultrasound of the testis is very sensitive at detecting testicular tumours. Chronicity of the inflammation was further supported by the thick fibrous capsule, vessel calcification and dystrophic intratesticular calcification shown in figure $1 \mathrm{~b}$. Soft tissue sarcomas are known to arise from chronic inflammation, such as that described in association with tropical ulcers [7].

In our patient, the detailed histopathological and immunohistochemical findings of the tumour satisfy the criteria for histological diagnosis of leiomyosarcoma. Distinction from other more common variants of testicular tumours is important, as reports indicate that leiomyosarcomas do well following radical surgical treatment [1]. On the other hand, radiotherapy or chemotherapy is often indicated in patients with other types of testicular tumours of the testis (i.e. seminomas or teratomas). The small number of cases of leiomyosarcoma in the literature makes it difficult to assess the natural history of the disease as it affects the testis. It does appear to be a slowgrowing tumour, as evidenced in our patient, who must have developed the tumour for a considerable length of time (15 years) before presenting to us. Yet radiological investigation and histopathology revealed a stage 1 testicular tumour.

Because of the rarity of testicular leiomyosarcoma, there are no clear guidelines for its treatment, however, radical orchidectomy appears adequate [8]. For paratesticular leiomyosarcoma, some oncologists have advocated adjunctive retroperitoneal and inguinal lymph node dissection or alternatively, external beam radiation. How- 
ever, these treatments have not been shown to add any benefit to the survival and/or the quality of life of the patient. Consequently, if the CT scan shows no secondary metastasis elsewhere, nothing more should be done after radical orchidectomy; only semiannual surveillance with imaging studies is required [5].

\section{Conclusion}

Radical orchidectomy seems to be the treatment of choice followed by close surveillance. The findings of this case report strongly suggest that long-standing chronic inflammation may be a predisposing factor for testicular leiomyosarcoma.

\section{References}

1 Yachia D, Auslaender L: Primary leiomyosarcoma of the testis. J Urol 1989;141:955-956.

2 Zahm SH, Fraumeni JF: The epidemiology of the soft tissue sarcoma. Semin Oncol 1997;24: 504-514.

3 Froehner M, Fischer R, Leike S, Hakenberg OW, Noack B, Wirth MP: Intratesticular leiomyosarcoma in a young man after high dose doping with Oral-Turinabol: A case report. Cancer 1999;86:1571-1575.
4 Washecka RM, Mariani AJ, Zuna RE, Honda SA, Chong CD: Primary intratesticular sarcoma: Immunohistochemical, ultrastructural and DNA flow cytometric study of the three cases with a review of the literature. Cancer 1996;77: 1524-1528.

5 Jenkins DG, Subbuswamy SG: Leiomyosarcoma of the spermatic cord: Case report. $\mathrm{Br} \mathrm{J}$ Surg 1972;59:408-410.
6 Renshaw A: Intratesticular leiomyosarcoma in a young man after high dose doping with oralturinabol. Cancer 2000;88:2195-2196.

7 Fletcher CD: Soft tissue sarcomas apparently arising in chronic tropical ulcers. Histopathology 1987;11:501-510.

8 Fagundes MA, Zeitman AL, Althausen AF, Coen JJ, Shipley WU: The management of spermatic cord sarcoma. Cancer 1996;77: 1873-1876. 